\title{
Sintering polycrystalline olivine and polycrystalline clinopyroxene containing trace amount of graphite from natural crystals
}

\author{
Yumiko Tsubokawa ${ }^{*}$ and Masahiro Ishikawa
}

\begin{abstract}
Graphite-bearing polycrystalline olivine and polycrystalline clinopyroxene with submicron to micron grain size were successfully sintered from a single crystal of naturally occurring olivine $\left(\mathrm{Fo}_{88-92} \mathrm{Fa}_{12-8}: \mathrm{Mg}_{1.76-1.84} \mathrm{Fe}_{0.16-0.24} \mathrm{SiO}_{4}\right)$ and a single crystal of naturally occurring clinopyroxene ( $\mathrm{Di}_{99} \mathrm{Hed}_{1}: \mathrm{Ca}_{0.92} \mathrm{Na}_{0.07} \mathrm{Mn}_{0.01} \mathrm{Mg}_{0.93} \mathrm{Fe}_{0.01} \mathrm{Al}_{0.06} \mathrm{Si}_{2} \mathrm{O}_{6}$ ). The milled powders of both these crystals were sintered under argon gas flow at temperatures ranging from 1130 to $1350{ }^{\circ} \mathrm{C}$ for $2 \mathrm{~h}$. As the sintering temperature increased, the average grain size of olivine increased from 0.2 to $1.4 \mu \mathrm{m}$ and that of clinopyroxene increased from 0.1 to $2.4 \mu \mathrm{m}$. The porosity of sintered samples remained at an almost-constant volume of 2-5\% for olivine and 3-4\% for clinopyroxene. The samples sintered from powders milled with ethanol exhibited trace amount of graphite, identified via Raman spectroscopy analysis. As the sintering temperature increased, the intensity of the graphite Raman peak decreased, compared with both olivine and clinopyroxene peaks. The carbon content of the sintered samples was estimated to be a few hundred ppm. The in-plane size $\left(L_{a}\right)$ of graphite in the sintered olivine was estimated to be $<15 \mathrm{~nm}$. Our experiments demonstrate new possibilities for preparing graphite-bearing silicatemantle mineral rocks, and this method might be useful in understanding the influence of the physical properties of graphite on grain-size-sensitive rheology or the seismic velocity of the Earth's mantle.
\end{abstract}

Keywords: Graphite, Olivine, Clinopyroxene, Submicron

\section{Introduction}

Carbon can occur throughout the near-surface regions of the Earth as well as deep within the Earth's interior (Hazen et al. 2012). The mantle is thought to contain the Earth's largest carbon reservoir, whereas the total estimated carbon concentration of the Earth's core is still being debated (e.g., Chi et al. 2014; Dasgupta et al. 2013; Sleep and Zahnle 2001; McDonough 2003). The solubility of carbon in olivine and other major silicate-mantle minerals is extremely low (Shcheka et al. 2006), and this implies that the carbon must occur in the form of carbonates, graphite, diamond, or in $\mathrm{C}-\mathrm{H}-\mathrm{O}$ fluids, etc. Since these minerals have different oxidation states, their formation will depend on the pressure, temperature, and oxygen fugacity $\left(\mathrm{O}_{2}\right)$ in the mantle (e.g., Frost and Wood

\footnotetext{
*Correspondence: tsubokawa-yumiko-nd@ynu.jp

Graduate School of Environment and Information Sciences, Yokohama National University, Yokohama 240-8501, Japan
}

1997; Kennedy and Kennedy 1976). According to these studies, carbon forms the minerals graphite or diamond under reducing conditions, which explains the prevalence of graphite/diamond in eclogites or peridotites from the lithosphere (e.g., Deines et al. 1991). The $f_{2}$ of the peridotitic mantle will remain in the graphite or diamond stability field to a depth of at least 100-150 km (Stagno and Frost 2010), implying that graphite or diamond would be the dominant host for carbon below 150-km depth, although Fe metal and carbides are also possible carbon hosts in the deep mantle.

Graphite attracts interest because it is thought to correspond with high levels of electrical conductivity in the mantle (e.g., Wang et al. 2013). In previous experimental studies concerning the influence of graphite on the electrical conductivity of a bulk aggregate, the graphite was prepared from graphite powders (Watson et al. 2010; Zhang and Yoshino 2017) and by coating a carbon film using a carbon coater (Yoshino and Noritake 
2011). Wang et al. (2013) used diamond powder to form graphite, and this changed the morphology of graphite to thin disk-like shapes. According to Wang et al. (2013), a weight of more than $1 \%$ ( 1.6 vol\%) of graphite is needed to enhance electrical conductivity in the mantle. However, the estimated carbon concentration in the upper mantle is only 20-250 ppm (Hirschmann and Dasgupta 2009; Saal et al. 2002; Trull et al. 1993), and the critical carbon content proposed by Wang et al. (2013) is much higher than a realistic amount of graphite.

In this study, a new method for sintering pulverized natural crystals of olivine and clinopyroxene into graphite-bearing polycrystalline olivine and polycrystalline clinopyroxene is described. We successfully sintered samples and produced trace amounts of graphite (estimated to be a few hundred ppm), which presumably contains a realistic amount of graphite in the mantle. Although $<1 \mathrm{wt} \%$ graphite may not play an important role in affecting the mantle's electrical conductivity, carbon is considered to be a critical element in determining the rheological properties of the mantle, e.g., carbon affects the melting phase relationships of minerals in mantle rocks (Dasgupta and Hirschmann 2006). Our method might be useful for future measurements on the physical properties of graphite-bearing rocks such as grain-sizesensitive rheology or the seismic velocity of the Earth's mantle.

\section{Experimental methods}

The materials used for the experiment were a crystal of San Carlos olivine with the composition $\mathrm{Fo}_{88-92} \mathrm{Fa}_{12-8}$ : $\mathrm{Mg}_{1.76-1.84} \mathrm{Fe}_{0.16-0.24} \mathrm{SiO}_{4}$ from Arizona, USA, and a crystal of clinopyroxene from Badakhshan, Afghanistan, with the composition $\mathrm{Di}_{99} \mathrm{Hed}_{1}: \mathrm{Ca}_{0.92} \mathrm{Na}_{0.07} \mathrm{Mn}_{0.01} \mathrm{Mg}_{0.93} \mathrm{Fe}_{0.01} \mathrm{Al}_{0.06} \mathrm{Si}_{2} \mathrm{O}_{6}$. Each grain was crushed into millimeter-sized fragments using an iron mortar and then ground for $>6 \mathrm{~h}$ using an automatic agate mortar. Finally, each sample was milled in high-purity ethanol or water with $0.5-\mathrm{mm}$ zirconia beads using a nano-pulverizer (THINKY, Japan) to a particle size of $<100 \mathrm{~nm}$. Each mineral powder was dried at $90{ }^{\circ} \mathrm{C}$ for more than $12 \mathrm{~h}$ and then uniaxially pressed at $\sim 150 \mathrm{MPa}$ for $10 \mathrm{~min}$ into a small disk with a $6 \mathrm{~mm}$ diameter and 0.7-1.9 mm thickness. Sintering was conducted using a Siliconit tube furnace under the flow of $99.995 \%$ pure argon $\left(\mathrm{N}_{2}<40.0 \mathrm{ppm}, \mathrm{O}_{2}<10.0 \mathrm{ppm}\right)$. Samples were placed on a nickel plate and sintered at various temperatures ranging from 1130 to $1350{ }^{\circ} \mathrm{C}$ for $2 \mathrm{~h}$. The heating and cooling rates were maintained at $5{ }^{\circ} \mathrm{C} / \mathrm{min}$. After sintering, the samples were cut and mirror-polished using a diamond sheet and then thermally etched for $0.5 \mathrm{~h}$ at $50-150{ }^{\circ} \mathrm{C}$ lower than the sintering temperatures in argon. The reason for the etching was to expose grain boundaries.
The observation of microstructures was performed using a field emission scanning electron microscope (SEM; JEOL, JSM-7001F) with an accelerating voltage of $3 \mathrm{kV}$. The grain size was calculated from SEM images using ImageJ software. The samples appeared to be too small to achieve precise measurements via the Archimedes method; thus, porosity was estimated using a portion of the total pore volume on the SEM images. X-ray diffraction (XRD) was performed to identify the phases present using an X-ray diffractometer (Rigaku RINT-2500) with $\mathrm{CuK}_{\alpha}$ radiation. Raman spectra of olivine, clinopyroxene, and graphite were obtained via laser Raman microspectroscopy (Renishaw Raman imaging microscope). The Raman spectra of clinopyroxene exhibited a strong fluorescent background, and these were processed by background subtraction and subsequent smoothing with Wire v4.0 Raman software.

\section{Results and discussion}

Several typical examples of the microstructures of sintered olivine and sintered clinopyroxene from powders milled with ethanol are shown in Fig. 1. Grains of both samples have a homogeneous texture and a polygonal shape. The average axis ratios for olivine and clinopyroxene grains were in the range of 1.5-1.6 and 1.5-1.7, respectively. After sintering of $2 \mathrm{~h}$, with increasing sintering temperature, the average grain size of sintered olivine increased from 0.2 to $1.4 \mu \mathrm{m}$ (at $1130-1350{ }^{\circ} \mathrm{C}$ ), and the grain size of sintered clinopyroxene increased from 0.1 to $2.4 \mu \mathrm{m}$ (at $1130-1280^{\circ} \mathrm{C}$ ). Porosities varied from 2 to $5 \mathrm{vol} \%$ for olivine and from 3 to $4 \mathrm{vol} \%$ for clinopyroxene. The crystal size distribution (CSD) in each sample is plotted as the frequency of the normalized grain size $\left(G / G_{\mathrm{m}}\right.$, $G_{\mathrm{m}}$ is average grain size) in Fig. 2. Olivine has a broad CSD with peaks in the range of $G / G_{\mathrm{m}}=0.6-1.2$, while clinopyroxene has a CSD demonstrating a unimodal peak at $G / G_{\mathrm{m}}=0.6-0.8$. The grain-growth exponent $n$ was not obtained in the different temperature experiments conducted over $2 \mathrm{~h}$; therefore, the grain-growth mechanisms for olivine and clinopyroxene could not be estimated. The characteristics of CSD in the clinopyroxene aggregates suggest that the dominant grain-growth process might be controlled by coalescence (Takajo et al. 1984) or by the Ostwald ripening (Sugimoto 1978). Alternatively, olivine aggregates might not reach a steady-state grain-growth condition based on the differences in the peak locations and the broadness of the grain size distribution.

Figure 3 shows the X-ray diffraction patterns of the mineral powders and sintered samples of olivine and clinopyroxene from powders milled with ethanol. Most of the pattern peaks represent Bragg's reflections for olivine and clinopyroxene in the aggregates. Figure 4 shows 

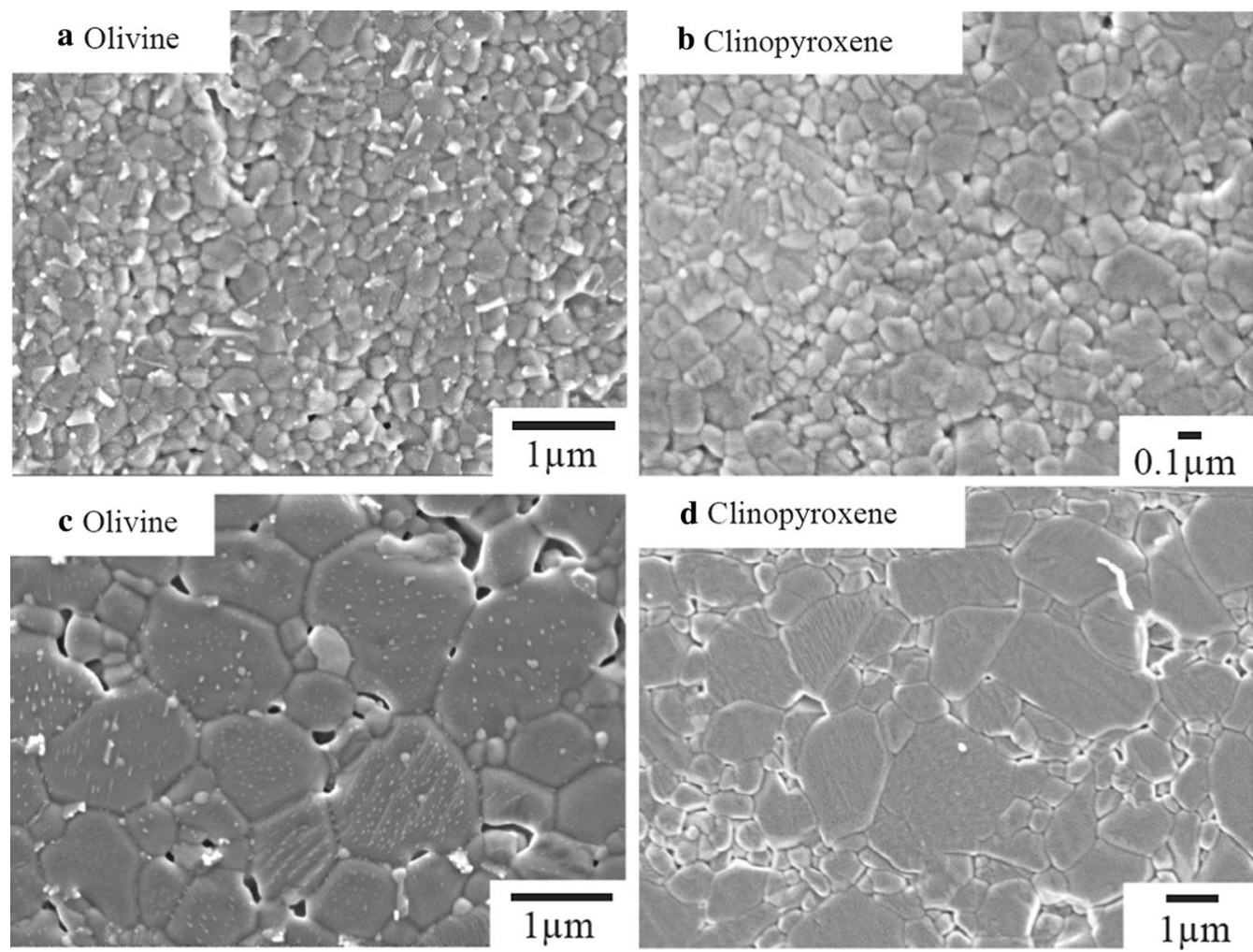

Fig. 1 Scanning electron microscopy (SEM) images of the sintered samples of $\mathbf{a}, \mathbf{c}$ olivine and $\mathbf{b}$, $\mathbf{d}$ clinopyroxene from powders milled with ethanol. In both samples, polished and thermal-etched cut sections are shown. Each sample was sintered for $2 \mathrm{~h}$ at different temperatures of $\mathbf{a} 1200^{\circ} \mathrm{C}$, b $1130^{\circ} \mathrm{C}, \mathbf{c} 1300^{\circ} \mathrm{C}$, and $\mathbf{d ~} 1280^{\circ} \mathrm{C}$. The small bright particles in the SEM images of sintered olivine were identified as magnetite from the thermaletching processes via energy-dispersive $\mathrm{X}$-ray spectroscopy (EDS) and Raman analysis
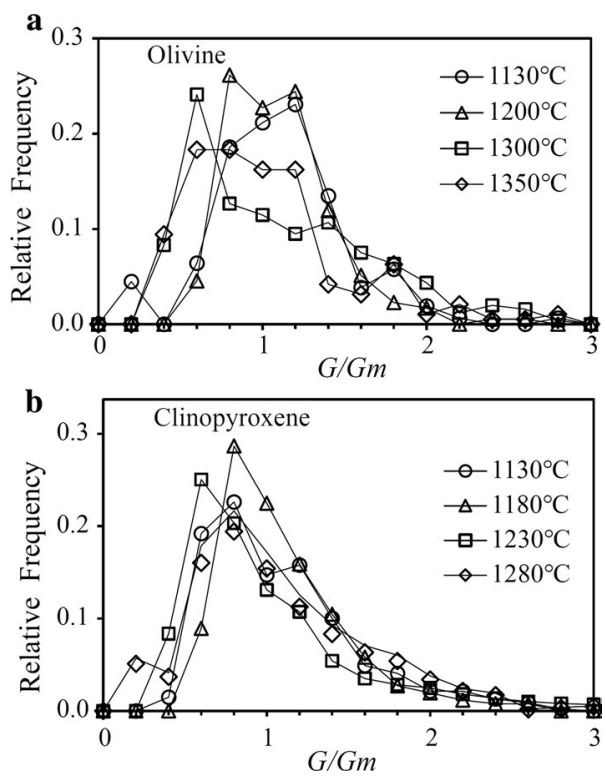

Fig. 2 Crystal size distribution (CSD) of $\mathbf{a}$ olivine and $\mathbf{b}$ clinopyroxene obtained from the samples sintered for $2 \mathrm{~h}$ at different temperatures the Raman spectra for the mineral powders, the sintered samples of olivine and clinopyroxene milled with water, and the sintered samples of olivine and clinopyroxene milled with ethanol. In the spectra of sintered samples from powders milled with ethanol, original olivine or clinopyroxene peaks were detected along with two broad peaks at 1350 and $1580 \mathrm{~cm}^{-1}$, corresponding to $\mathrm{sp}^{2}$-bonded graphitic carbon. These graphite peaks were not observed in the surface samples but in a cut section of the samples, implying that surface carbon was at least oxidized under $f \mathrm{O}_{2}$ conditions in our experiments. It is also obvious from the Raman spectra that the intensity of graphite peaks decreases with increasing sintering temperature (Fig. 5). This feature is found in the spectra of both sintered olivine and sintered clinopyroxene. The XRD patterns of both sintered samples suggest that the content of graphite in the sintered samples is very low and below the XRD detection limit. Although electron probe microanalysis (EPMA) of carbon concentrations is quite difficult due to the contamination of atmospheric carbon dioxide $\left(\mathrm{CO}_{2}\right)$ on the sample surface, we 

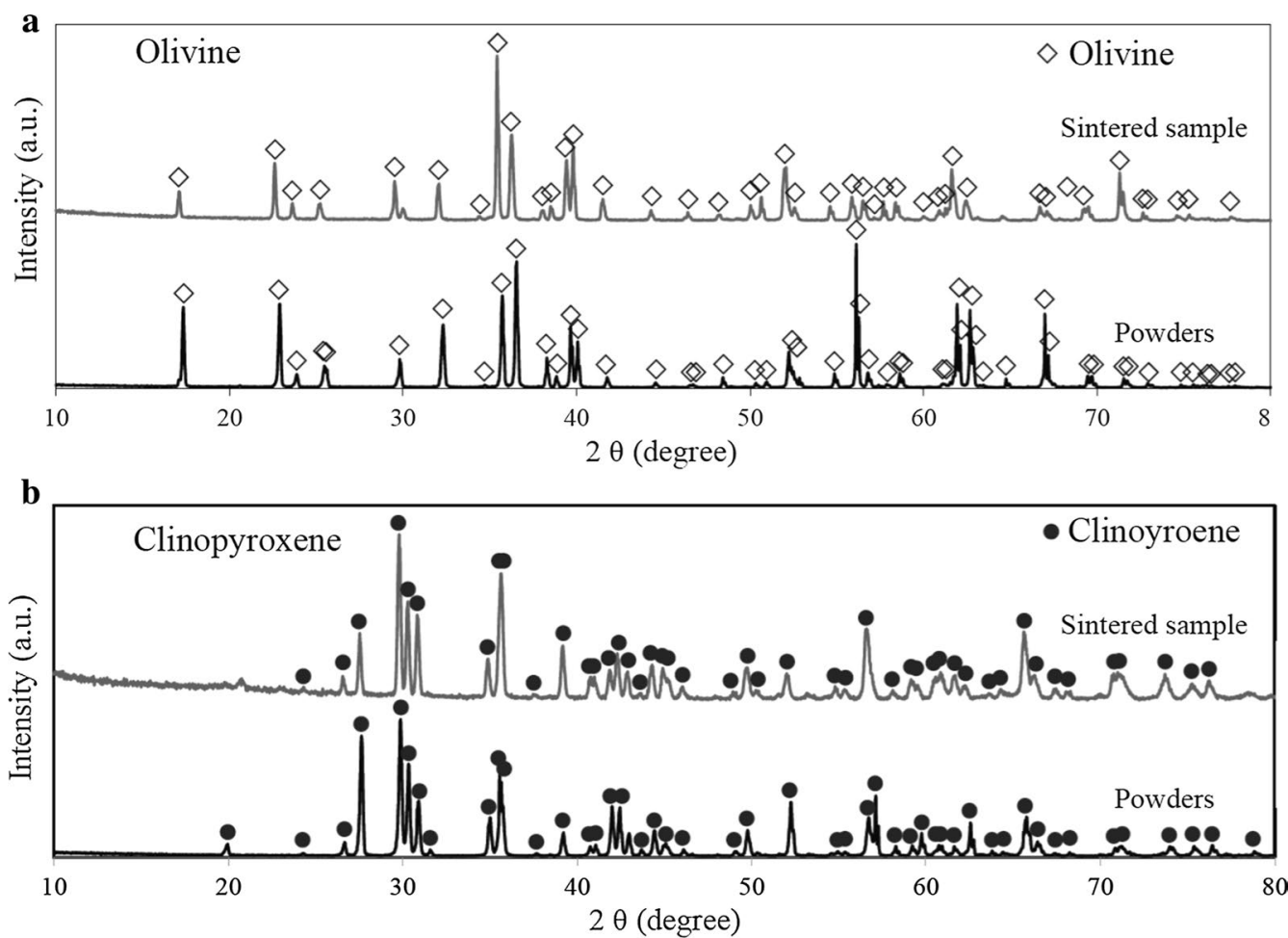

Fig. 3 X-ray diffraction patterns from the mineral powders and sintered samples of $\mathbf{a}$ olivine and $\mathbf{b}$ clinopyroxene from powders milled with ethanol. Olivine and clinopyroxene samples were sintered at 1300 and $1280^{\circ} \mathrm{C}$, respectively. The XRD patterns of both sintered samples did not exhibit graphite peaks (e.g., at a $2 \theta$ value of $\left.26^{\circ}\right)$

compared the difference in EPMA values for carbon between the graphite-bearing sample and the "graphitefree" sample revealed by Raman analysis. The graphite content was not precisely analyzed, but the estimated carbon concentration is a few hundred ppm. As both starting materials did not contain any carbon-bearing minerals, there is a possibility that the ethanol solvent or carbon dioxide from the atmosphere could be responsible for the presence of graphite in the sintered samples. The powders that were milled with water rather than ethanol and then sintered did not exhibit a graphite Raman peak, and therefore, this might be significant in determining the presence of graphite.

As mentioned above, $f \mathrm{O}_{2}$ is an important parameter governing the carbon-mineral type. If the presence of remaining graphite within the inner part of the sample is considered, $f \mathrm{O}_{2}$ is estimated to be at most $10^{-4} \mathrm{~Pa}$ at the peak temperature $\left(\sim 1350{ }^{\circ} \mathrm{C}\right)$ of our experiments according to the Ellingham diagram for the formation of oxides as a function of temperature. This is quite significantly lower than the theoretical $f \mathrm{O}_{2}$ value of about $10^{-1}$ to $10^{-2} \mathrm{~Pa}$ calculated using the composition of argon gas. The nickel plate under the sample was partly oxidized after sintering, and therefore, nickel-oxygen reactions should have controlled $f \mathrm{O}_{2}$ in the furnace. Although the oxygen fugacity buffered by $\mathrm{Ni}-\mathrm{NiO}\left(\mathrm{fO}_{2}\right.$ of $10^{1}$ to $10^{2}$ $\mathrm{Pa}$ at $1350{ }^{\circ} \mathrm{C}$ ) is also above the $f \mathrm{O}_{2}$ stability of graphite, the nickel plate might have caused reduced $\mathrm{fO}_{2}$ close to the sample. The absence of graphite at the surface of the sample implies that the outer surface of sample was exposed to a more oxidizing environment. The reason for these ranges in $f_{2}$ is not well understood, but it could be related to the decreasing rate of the temperature. The $\mathrm{fO}_{2}$ stability of graphite decreases with increasing temperature, which may explain the gradual decrease in graphite in Raman bands with increasing sintering temperature. The results show that to obtain samples that have a constant quantity of graphite, sintering experiments should be performed at a much lower $f_{2}\left(<10^{-4} \mathrm{~Pa}\right)$ with a gas other than argon (e.g., $\mathrm{CO} / \mathrm{CO}_{2}$ gas mixes) or under highvacuum conditions (about $<10^{-3} \mathrm{~Pa}$ ).

The Raman spectrum of a highly crystalline graphite particle generally has only one peak at $1580 \mathrm{~cm}^{-1}$, known as the $G$ band. However, in our sintered samples an additional $D$ band occurs at $1350 \mathrm{~cm}^{-1}$, implying some structural disorder ascribed to impurities, edges, and other defects (Tuinstra and Koenig 1970; Pimenta et al. 2007). The ratio of the $D$ and $G$ band intensities $\left(I_{D} / I_{G}\right)$ can be 

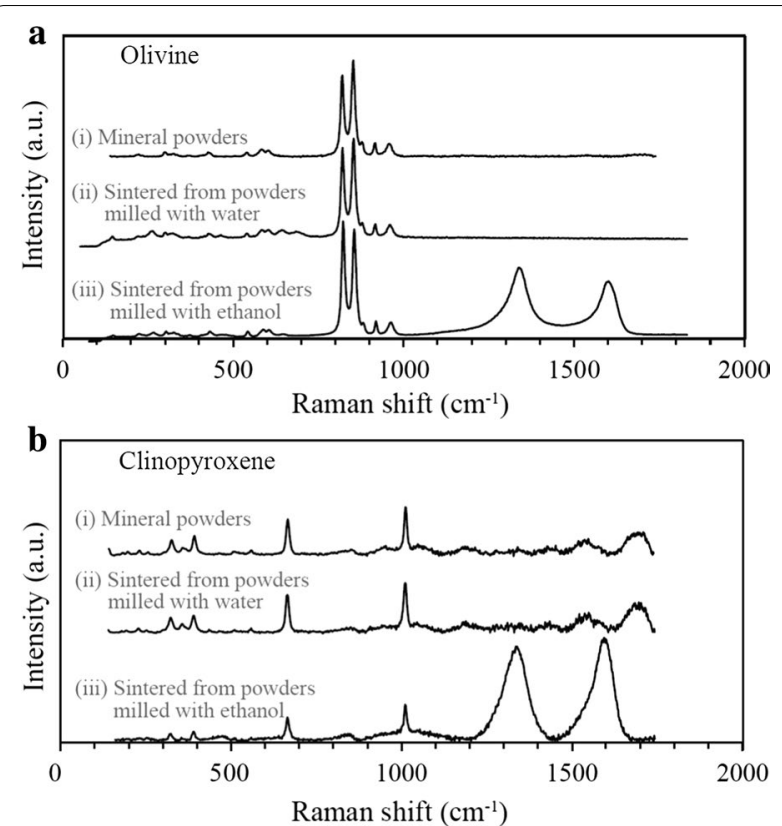

Fig. 4 Raman spectra of mineral powders and samples that were sintered at $1300^{\circ} \mathrm{C}$ for $\mathbf{a}$ olivine and $1180^{\circ} \mathrm{C}$ for $\mathbf{b}$ clinopyroxene. (i) Mineral powders. (ii) Sintered from powders milled with water. (iii) Sintered from powders milled with ethanol. Graphite peaks were not found in sintered samples where the powders were milled using water rather than ethanol

used as a parameter for quantifying the disorder, and these values inversely vary with the crystallite size $L_{a}$ (in the direction of the graphite plane). The sintered samples exhibit a broad Raman spectral feature of $D$ and $G$ bands and a high $I_{D} / I_{G}$, implying a large amount of disorder or a very small crystallite size. Graphite particles were not identified in the sintered samples, when these samples were investigated via SEM and TEM, and therefore, graphite is expected to occur as less than few nanometer-sized particles. The crystallite size $\left(L_{a}\right)$ of graphite in sintered olivine was estimated to be $<15 \mathrm{~nm}$. This is calculated by using the following empirical formula proposed by Cançado et al. (2006):

$$
L_{a}(\mathrm{~nm})=\left(2.4 \times 10^{-10}\right) \lambda_{l}^{4}\left(I_{D} / I_{G}\right)^{-1}
$$

where $\lambda_{l}$ is the laser line wavelength in nanometers. According to Graf et al. (2007), the relative intensity of the $G$ and $D^{\prime}$ bands ( $D^{\prime}$ band: the second-order band at around $2700 \mathrm{~cm}^{-1}$ ) is an indicator of the number of stacked layers in the graphite. Although the intensity of the $D^{\prime}$ band was not precisely obtained due to the overlapping high-fluorescence background even in the case of olivine spectra, few-layers to multilayers of graphite are expected in sintered olivine.

Recently, nanocrystalline materials have received wide attention because they potentially influence creep
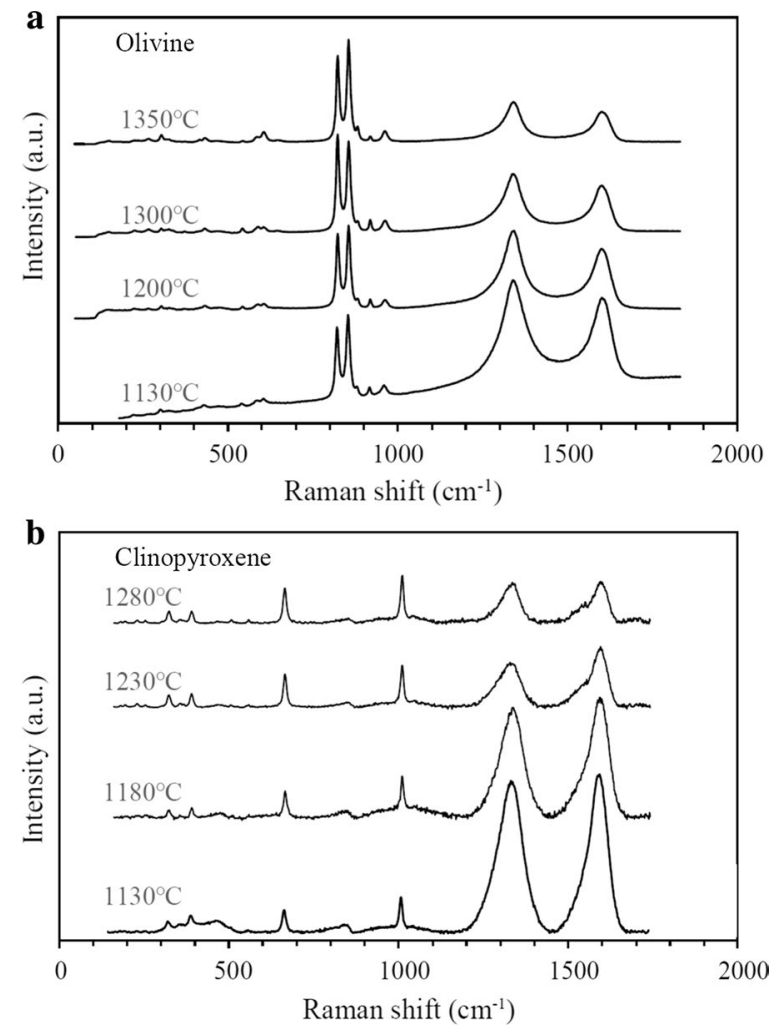

Fig. 5 Raman spectra of sintered $\mathbf{a}$ olivine and $\mathbf{b}$ clinopyroxene. Samples were sintered for $2 \mathrm{~h}$ at different temperatures: $1130-1350^{\circ} \mathrm{C}$ for olivine and $1130-1280^{\circ} \mathrm{C}$ for clinopyroxene

behavior and earthquake rupture nucleation and propagation (Chen et al. 2013). For example, Koizumi et al. (2010) successfully obtained a highly dense and finegrained aggregate of mantle composites that included olivine (porosity $0.65 \mathrm{vol} \%, 720 \mathrm{~nm}$ ) and clinopyroxene (porosity $0.13 \mathrm{vol} \%, 1.1 \mu \mathrm{m})$. In their study, the olivine powder was vacuum sintered at $1240{ }^{\circ} \mathrm{C}\left(\mathrm{Fo}_{90} \mathrm{Fa}_{10}\right.$ : $\mathrm{Mg}_{1.8} \mathrm{Fe}_{0.2} \mathrm{SiO}_{4}$ ) and the diopside powder (an end-member of Ca-pyroxene: $\mathrm{CaMgSi}_{2} \mathrm{O}_{6}$ ) was sintered at $1260^{\circ} \mathrm{C}$. We compared the sintered samples from this study with those of Koizumi et al. (2010) at temperatures closer to those in their experiments and obtained olivine aggregates of a similar grain size $(690 \mathrm{~nm})$ with $1200{ }^{\circ} \mathrm{C}$ sintering. However, the grain size of sintered clinopyroxene $(2.4 \mu \mathrm{m})$ at $1280^{\circ} \mathrm{C}$ in the present study was about twice as large as that in the study by Koizumi et al. (2010). This difference in grain size might be related to the content of impurities in our sample (e.g., $\mathrm{Na}_{2} \mathrm{O}, \mathrm{Al}_{2} \mathrm{O}_{3}, \mathrm{FeO}$, and $\mathrm{MnO})$. It was not possible to obtain the highly dense samples that Koizumi et al. (2010) obtained, but we successfully obtained graphite-bearing polycrystalline olivine and polycrystalline clinopyroxene with a submicron to micron grain size. These graphite-bearing fine-grained 
aggregates may be useful for future measurements to understand the influence of graphite on grain-size-sensitive deformation behavior of the Earth's mantle.

\section{Conclusions}

Polycrystalline olivine and polycrystalline clinopyroxene containing trace amounts of graphite were successfully sintered from natural crystals of olivine and clinopyroxene. Graphite was identified in the sintered samples using Raman spectroscopy but was only evident in samples that were sintered from powders milled with ethanol. The intensity of the graphite Raman peak decreased as the sintering temperature increased from 1130 to $1350{ }^{\circ} \mathrm{C}$. The in-plane crystallite size of graphite in the sintered olivine was estimated to be $<15 \mathrm{~nm}$, and the number of stacked layers in the graphite was considered to range from few-layers to multilayers.

\section{Abbreviations}

$\mathrm{fO}_{2}$ : oxygen fugacity; SEM: scanning electron microscope; XRD: X-ray diffraction; EDS: energy-dispersive $X$-ray spectroscopy; EPMA: electron probe microanalysis.

\section{Authors' contributions}

YT designed this study, conducted the analysis, and wrote the paper. Both the authors discussed and devised the sintering experiment. Both authors read and approved the final manuscript.

\section{Acknowledgements}

We acknowledge the reviewers for their constructive reviews and Prof. Takeshita for his editorial efforts. This work was supported by Japan Society for the Promotion of Science KAKENHI Grant No. 26109006.

\section{Competing interests}

The authors declare that they have no competing interests.

\section{Publisher's Note}

Springer Nature remains neutral with regard to jurisdictional claims in published maps and institutional affiliations.

Received: 9 April 2017 Accepted: 7 September 2017 Published online: 16 September 2017

\section{References}

Cançado LG, Takai K, Enoki T, Endo M, Kim YA, Mizusaki H, Jorio A, Coelho LN, Magalhaes-Paniago R, Pimenta MA (2006) General equation for the determination of the crystallite size $L_{a}$ of nanographite by Raman spectroscopy. Appl Phys Lett 88:163106

Chen X, Madden AS, Bickmore BR, Reches Z (2013) Dynamic weakening by nanoscale smoothing during high-velocity fault slip. Geology 41(7):739-742

Chi H, Dasgupta R, Duncan M, Shimizu N (2014) Partitioning of carbon between Fe-rich alloy melt and silicate melt in a magma ocean -implications of the abundance and origin of volatiles in Earth, Mars, and the Moon. Geochim Cosmochim Acta 139(15):447-471

Dasgupta R, Hirschmann MM (2006) Melting in the Earth's deep upper mantle caused by carbon dioxide. Nature 440:659-662

Dasgupta R, Chi H, Shimizu N, Buono AS, Walker D (2013) Carbon solution and partitioning between metallic and silicate melts in a shallow magma ocean: implications for the origin and distribution of terrestrial carbon. Geochim Cosmochim Acta 102(1):191-212

Deines P, Harris JW, Robinson DN, Gurney JJ, Shee SR (1991) Carbon and oxygen isotope variations in diamond and graphite eclogites from Orapa, Botswana, and the nitrogen content of their diamonds. Geochim Cosmochim Acta 55(2):515-524

Frost DJ, Wood BJ (1997) Experimental measurements of the fugacity of CO2 and graphite/diamond stability from 35 to $77 \mathrm{kbar}$ at 925 to $1650{ }^{\circ} \mathrm{C}$. Geochim Cosmochim Acta 61 (8):1565-1574

Graf D, Molitor F, Ensslin K, Stanpfer C, Jungen A, Hierold C, Wirtz L (2007) Spatially resolved raman spectroscopy of single- and few-layer graphene. Nano Lett 7(2):238-242

Hazen RM, Hemley RJ, Mangum AJ (2012) Carbon in earth's interior: storage, cycling, and life. EOS Trans Am Geophys Union 93(2):17-28

Hirschmann MM, Dasgupta R (2009) The H/C ratios of Earth's near-surface and deep reservoirs, and consequences for deep Earth volatile cycles. Chem Geol 262:4-16

Kennedy CS, Kennedy GC (1976) The equilibrium boundary between graphite and diamond. J Geophys Res 81:2467-2470

Koizumi S, Hiraga T, Tachibana C, Tasaka M, Miyazaki T, Kobayashi T, Takamasa A, Ohashi N, Sano S (2010) Synthesis of highly dense and fine-grained aggregates of mantle composites by vacuum sintering of nano-sized mineral powders. Phys Chem Miner 37:505-518

McDonough WF (2003) Compositional model for the Earth's core. In: Carlson RW (ed) The mantle and core, treatise on geochemistry, vol 2. ElsevierPergamon, Oxford, pp 547-568

Pimenta MA, Dresselhaus G, Dresselhaus MA, Cançado LG, Jorio A, Saito R (2007) Studying disorder in graphite-based systems by Raman spectroscopy. Phys Chem Chem Phys 9:1276-1291

Saal AE, Hauri EH, Langmuir H, Perfit MR (2002) Vapour undersaturation in primitive mid-ocean-ridge basalt and the volatile content of Earth's upper mantle. Nature 419:451-455

Shcheka SS, Wiedenbeck M, Frost DJ, Keppler H (2006) Carbon solubility in mantle minerals. Earth Planet Sci Lett 245:730-742

Sleep N, Zahnle K (2001) Carbon dioxide cycling and implications for climate on ancient Earth. J Geophys Res Planets 106(E125):1373-1399

Stagno V, Frost DJ (2010) Carbon speciation in the asthenosphere: Experimental measurements of the redox conditions at which carbonate-bearing melts coexist with graphite or diamond in peridotite assemblages. Earth Planet Sci Lett 300:72-84

Sugimoto T (1978) Kinetics of reaction-controlled Ostwald ripening of precipitates in the steady state. J Colloid Interface Sci 63(2):369-377

Takajo S, Kaysser WA, Petzow G (1984) Analysis of particle growth by coalescence during liquid phase sintering. Acta Metall 32(1):107-113

Trull T, Nadeau S, Pineau F, Polve M, Javoy M (1993) C-He systematics in hotspot xenoliths: implications for mantle carbon contents and carbon recycling. Earth Planet Sci Lett 118:43-64

Tuinstra F, Koenig JL (1970) Characterization of graphite fiver surfaces with Raman spectroscopy. J Compos Mater 4(4):492-499

Wang D, Karato S, Jiang Z (2013) An experimental study of the influence of graphite on the electrical conductivity of olivine aggregates. Geophys Res Lett 40(10):2028-2032

Watson HC, Roberts JJ, Tyburczy JA (2010) Effect of conductive impurities on electrical conductivity in polycrystalline olivine. Geophys Res Lett 37(2):L02302

Yoshino T, Noritake F (2011) Unstable graphite films on grain boundaries in crustal rocks. Earth Planet Sci Lett 306:186-192

Zhang B, Yoshino T (2017) Effect of graphite on the electrical conductivity of the lithospheric mantle. Geochem Geophy Geosy 18(1):23-40 